\title{
Evaluation of Noise of Strain Wave Gearing by Vibration Measurement*
}

\author{
Masashi YAMANAKA $^{* *}$, Hideki MAEDA
and Xin Yue ZHANG**** \\ ${ }^{* *}$ School of Engineering, Tohoku University, \\ 6-6-01 Aramaki-Aoba, Aoba-ku, Sendai, 980-9579 Japan \\ E-mail: yamanaka@elm.mech.tohoku.ac.jp \\ ***Mitutoyo Corporation (Former; Tohoku University), \\ 2200 Simokuri-cho, Utsunomiya-shi, Tochigi, 321-0923 Japan \\ ****Harmonic Drive Systems Inc. \\ 1856-1 Hodakamaki, Azumino-shi, Nagano, 399-8305 Japan
}

\begin{abstract}
This paper deals with the radiated noise of strain wave gearing, which is a kind of $\mathrm{K}-\mathrm{H}-\mathrm{V}$ type planetary gears having features of light weight and high reduction ratio. The vibration of the Flex Spline $(\mathrm{F} / \mathrm{S})$, which is an element of strain wave gearing shaped like a thin circular cup, is considered to be a main cause of the noise. Theoretically, the magnitude of sound power is expected to increase in proportion to the square of the amplitude of the displacement of the $\mathrm{F} / \mathrm{S}$ in the radial direction. The displacements in 3 models are calculated using FEM. The vibration of the $\mathrm{F} / \mathrm{S}$ and the sound power are measured using the fixed-F/S experimental apparatus. It is confirmed that the relationship between the vibration of the F/S and the sound power agrees well with the theory, and that the vibration of the F/S is the main cause of radiated noise. Moreover, the radiated noise with various rotary speeds, loaded torques and assembly errors is measured and examined. The influences of rotary speed and torque are explained by the noise-generation mechanism on the basis of the velocity amplitude of the F/S. The noise becomes large with the increase of assembly error, but the amplitude of displacement is not increased. This is confirmed by the resonance between the F/S and experiment apparatus.
\end{abstract}

Key words: Gear, Strain Wave Gearing, Noise, Vibration, Flex Spline, Assembly Error, Rotary Speed

\section{Introduction}

Strain wave gearing is a kind of K-H-V-type planetary gears and consists of the following three components: an elliptical wave generator $(\mathrm{W} / \mathrm{G})$, a flex spline $(\mathrm{F} / \mathrm{S})$, which is a thin external gear that is elliptically deformed by $\mathrm{W} / \mathrm{G}$, and a circular spline $(\mathrm{C} / \mathrm{S})$, which is a thick internal gear, the large number of teeth of which mesh with those of the F/S. Strain wave gearings are small and lightweight, and can produce a high gear ratio; therefore, they are used in many precision machines, such as industrial robots. There are many research works on strain wave gearings, including stress measurements of the $\mathrm{F} / \mathrm{S}^{(1)}$, stress analysis by the finite element method $(\mathrm{FEM})^{(2)-(4)}$, and the evaluation of the characteristics of load transmission ${ }^{(5)}$, to improve the strength of $\mathrm{F} / \mathrm{S}$ deformed repeatedly. Moreover, regarding torsional vibration caused by rotary error ${ }^{(6)}$, experiments ${ }^{(7)}$ and simulations $^{(8)}$ have been carried out. However, as far as we know, there are no reports on the 
noise generated by strain wave gearing.

In this study, we considered that the out-of-plane vibration of the F/S subjected to repeated elastic deformation is the main cause of the noise. To demonstrate our assumption, the noise radiated from the strain wave gearing and the vibrations of the F/S were measured to compare and discuss their characteristics. In particular, four factors, i.e., the module, loaded torque, input rotary speed, and assembly error, are focused on in the noise evaluation to clarify the noise-generation mechanism in the strain wave gearing.

\section{Estimation of Noise-Generation Mechanism}

$\mathrm{W} / \mathrm{G}$ is incorporated in the F/S and deforms the shape of the F/S to an ellipse. When focusing on one point on the lateral side of the F/S cylinder, the point moves in the radial direction because $\mathrm{W} / \mathrm{G}$ rotates with respect to $\mathrm{F} / \mathrm{S}$. Since the F/S and $\mathrm{W} / \mathrm{G}$ mesh at two points on the major axis of the ellipse, it is considered that the point mentioned above is subjected to sinusoidal out-of-plane vibration at frequency $f_{w}$, which is twice the rotation frequency of $\mathrm{W} / \mathrm{G}$. The sound power $W$ is expressed as

$$
W=\sigma \rho_{0} c \overline{v^{2}} S
$$

using the equation of radiation sound from the baffle board ${ }^{(9)}$. Here, $\sigma$ is the radiation efficiency, $\rho_{0}$ is the density of air, $c$ is the sound velocity, $v$ is the vibration velocity, and $S$ is the surface area of the plate. Therefore, if the vibration of the $\mathrm{F} / \mathrm{S}$ is the main factor of the noise, it is considered that the sound power increases in proportion to the mean-square value of the vibration velocity $\overline{v^{2}}$.

First, the deformed shape of the F/S is determined by FEM analysis and the vibration waveform while the $\mathrm{W} / \mathrm{G}$ rotation is being estimated. Figure 1 summarizes the specifications of three types of strain wave gearings with different gear ratios used in the experiment described later. On the basis of these specifications, as shown in Fig. 2, the F/S is modeled into a cup shape in which the teeth are omitted for simplicity, and the W/G is modeled into a solid elliptic cylinder, the center of which is removed (only the upper halves are shown in Fig. 2). The flange of the F/S (left side in Fig. 2) is fixed, then the W/G is placed inside the F/S in such a way that the W/G does not come into contact with the F/S. Subsequently, the $\mathrm{W} / \mathrm{G}$ is forcibly displaced so that the vertex on the major axis is $b / 2$ from the center, which causes the $\mathrm{F} / \mathrm{S}$ to deform. It is considered that the presence of the $\mathrm{C} / \mathrm{S}$ limits the range of the $\mathrm{F} / \mathrm{S}$ deformation caused by the $\mathrm{W} / \mathrm{G}$, and the $\mathrm{C} / \mathrm{S}$ itself is not modeled. However, the effect of the $\mathrm{C} / \mathrm{S}$ is expressed by applying the forced displacement so that a point on the major axis of the F/S is displaced by $\left(c_{r}-d_{t}\right) / 2$ from the center. Considering the effect of torque transmission caused by the meshing of the teeth between the $\mathrm{C} / \mathrm{S}$ and $\mathrm{F} / \mathrm{S}$, the tooth profile part of which are omitted in the model, upon the deformation of the $\mathrm{F} / \mathrm{S}$, torque is applied with respect to the mesh region (hatched area in Fig. 2). It is assumed that the angle of the mesh region is $54^{\circ}$ in the circumferential direction because the mesh rate between the $\mathrm{F} / \mathrm{S}$ and $\mathrm{C} / \mathrm{S}$ is approximately $30 \%{ }^{(10)}$, and the width of the region is equal to the thickness of the $\mathrm{W} / \mathrm{G}$.

Figure 3 shows the waveform of the displacement of the $\mathrm{F} / \mathrm{S}$ with different modules when the $\mathrm{W} / \mathrm{G}$ rotates $360^{\circ}$, as obtained by FEM analysis. The loaded torque is $40 \mathrm{Nm}$. The $\mathrm{F} / \mathrm{S}$ vibrates sinusoidally; when the module increases, the displacement amplitude increases. When the gear ratio increases, the module decreases and the number of teeth increases, as shown in Fig. 1, because the pitch circle diameters of the three C/Ss are identical. The observation of the mesh region between the $\mathrm{F} / \mathrm{S}$ and $\mathrm{C} / \mathrm{S}$ reveals that the $\mathrm{F} / \mathrm{S}$ moves in the circumferential direction while the $\mathrm{F} / \mathrm{S}$ oscillates in the radial direction. Therefore, to avoid interference under the condition of a large module, the F/S should move markedly (generate the wave) in the radial direction. To realize this, the ratio of the major to minor axis of the 


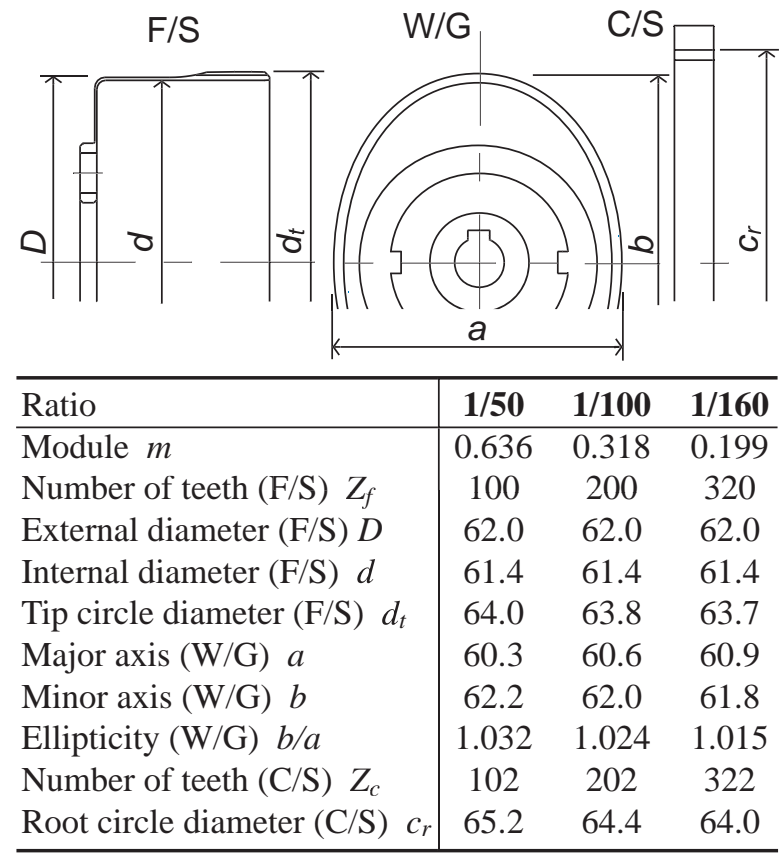

Fig. 1 Specifications of strain wave gearing

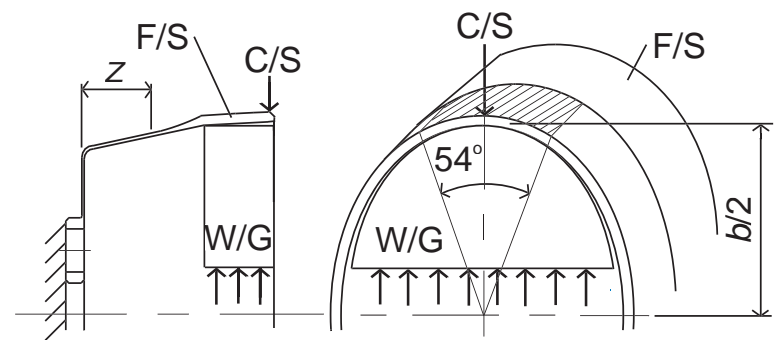

Fig. 2 Model of strain wave gearing and its constraint condition

$\mathrm{W} / \mathrm{G}$ ellipse is designed to become large as the module increases. On the basis of the results shown in Fig. 3, it is considered that the F/S is subjected to harmonic vibration. Therefore,

$$
\begin{aligned}
\overline{v^{2}} & =\frac{1}{2} v_{a}^{2} \\
v_{a} & =a \omega
\end{aligned}
$$

hold. Here, $v_{a}$ is the vibration amplitude, $a$ is the displacement amplitude, and $\omega$ is the angular frequency. It is expected that the noise generated by the large-module wave gears, for which a is theoretically high, is large because $\overline{v^{2}}$ is also large.

\section{Experimental Apparatus and Method}

\subsection{Experimental apparatus}

When strain wave gearing is used as a reduction gear, in general, the $\mathrm{W} / \mathrm{G}$ is used as input, the $\mathrm{C} / \mathrm{S}$ is fixed, and $\mathrm{F} / \mathrm{S}$ is used as output. It is difficult to measure the out-of-plane vibration at a particular position on the lateral side of the $\mathrm{F} / \mathrm{S}$ because it rotates. Therefore, an experimental apparatus in which the F/S is fixed, as shown in Fig. 4, was designed and developed. In this apparatus, the $\mathrm{W} / \mathrm{G}$ was used as input, the $\mathrm{F} / \mathrm{S}$ was fixed, and the $\mathrm{C} / \mathrm{S}$ was used as output. In addition, the hollow output shaft was placed on the same side as the input shaft to facilitate the measurement of the $\mathrm{F} / \mathrm{S}$ vibration. The strain wave gearing was driven 


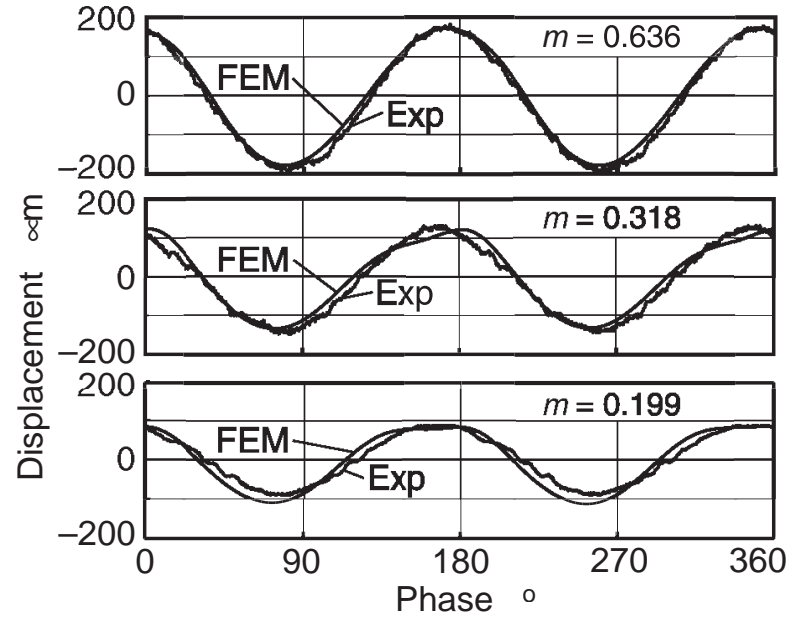

Fig. 3 Waveforms of displacement of F/S obtained by FEM and experiment

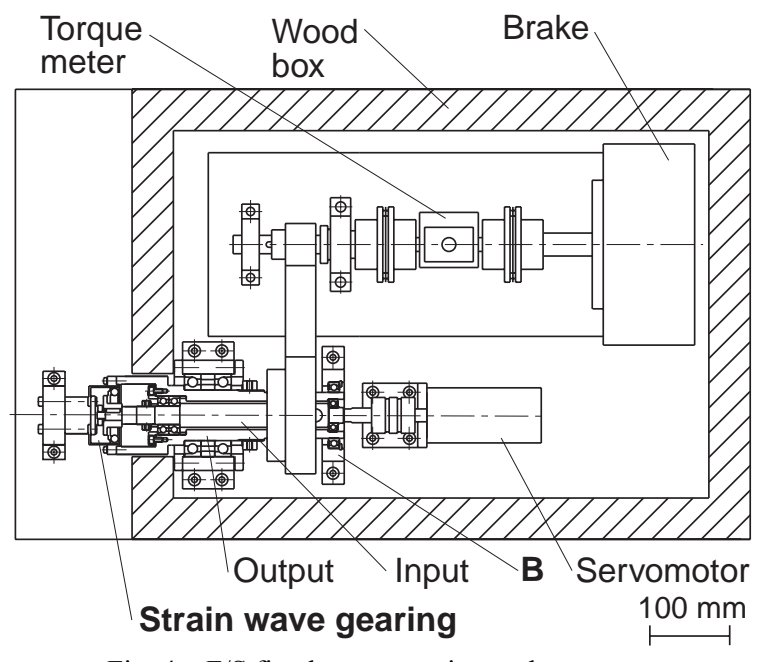

Fig. 4 F/S fixed type experimental apparatus

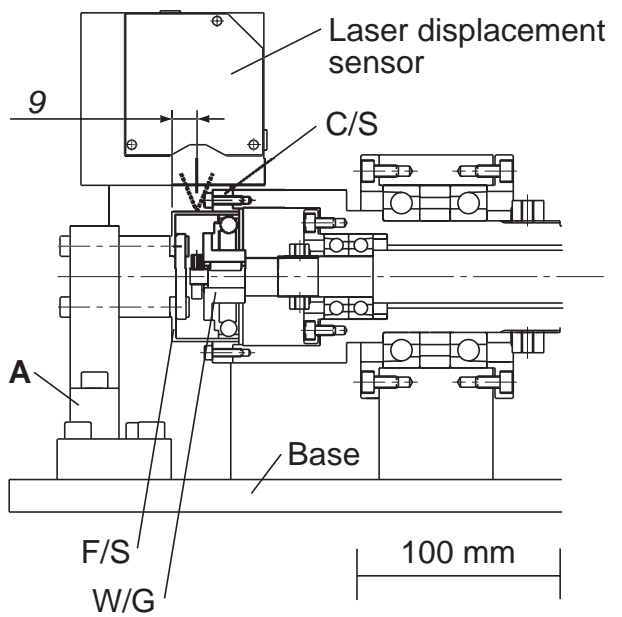

Fig. 5 Measurement of vibration of F/S using laser displacement sensor

using a servo motor, and a loaded torque was applied using an electromagnetic brake. As shown in Fig. 5, the F/S vibration was measured on its lateral side at a position $9 \mathrm{~mm}$ from the flange surface, using a laser displacement sensor. 


\subsection{Experimental method}

Three types of strain wave gearing with identical external diameters but different gear ratios (Fig. 1) were used in this study. The strain wave gearings were operated under different conditions of loaded torque, input rotary speed, and assembly error, to measure the vibration and noise generated under each condition. During measurement, the experimental apparatus was enclosed within a wooden box to which an acoustic absorbent was attached on the inside, as shown in Fig. 4, to prevent the effect of sound radiated from the motor and the electromagnetic brake. The noise level was evaluated in terms of sound power, on the basis of the Japanese Industrial Standard (JIS) Z8736 ${ }^{(11)}$. In addition, spectral analysis was also carried out to determine the frequency characteristics of the noise. The microphone used to correct the noise was placed vertically at a distance of $20 \mathrm{~mm}$ from the $\mathrm{F} / \mathrm{S}$ lateral side.

\section{Measurement Results and Discussion}

\subsection{Determination of main factor of vibration}

The measured vibration of the F/S is shown in Fig. 3 along with the FEM results. The loaded torque was $40 \mathrm{Nm}$ and the input rotary speed was 3000 min-1. The waveform changes negligibly when the input rotary speed is changed. The experimental results agree well with the FEM results. The displacement amplitude is obtained from the measured vibration waveform and is used to calculate the velocity amplitude using Eq. (3). The relationship between the velocity amplitude and the module is shown in Fig. 6. As expected, the velocity amplitude increases with increasing module. Figure 7 shows the relationship between module and sound power. Sound power increases with increasing module. Figure 8 shows the relationship between the velocity amplitude and sound power on the basis of the results shown in Figs. 6 and 7. Sound power increases proportionally with the square of the velocity amplitude. This relationship is in agreement with the theory expressed using Eqs. (1) and (2).

Next, the $\mathrm{F} / \mathrm{S}$ vibration and sound power in a rotating $\mathrm{W} / \mathrm{G}$ were measured under the condition that power transmission is prevented by removing the $\mathrm{C} / \mathrm{S}$ in order to examine the effect of vibration caused by teeth meshing on noise. The results are shown in Figs. 6 and 7 . The velocity amplitude is slightly lower than that when the $\mathrm{F} / \mathrm{S}$ meshes with the $\mathrm{C} / \mathrm{S}$; however, the velocity amplitude increases as module becomes large. In contrast, sound power is higher when the $\mathrm{F} / \mathrm{S}$ does not mesh with the $\mathrm{C} / \mathrm{S}$ than when it does, and increases as module becomes large. The rate of increase in sound power with respect to the increase

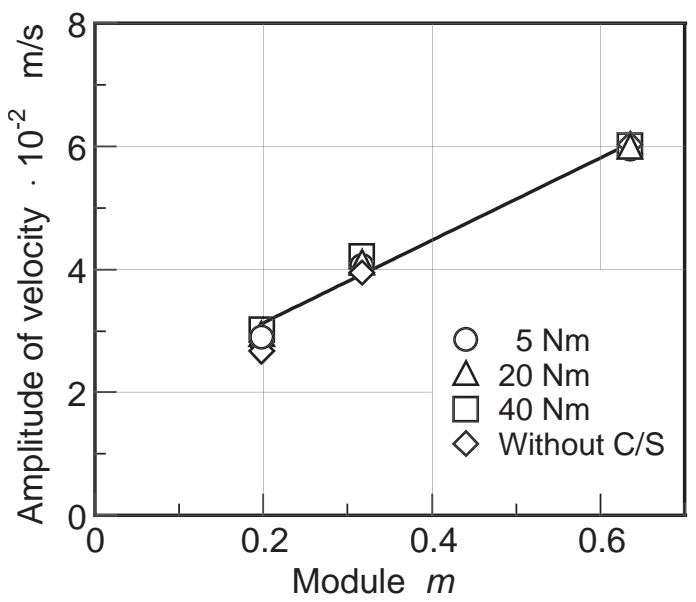

Fig. 6 Relation between amplitude of velocity of F/S and module 


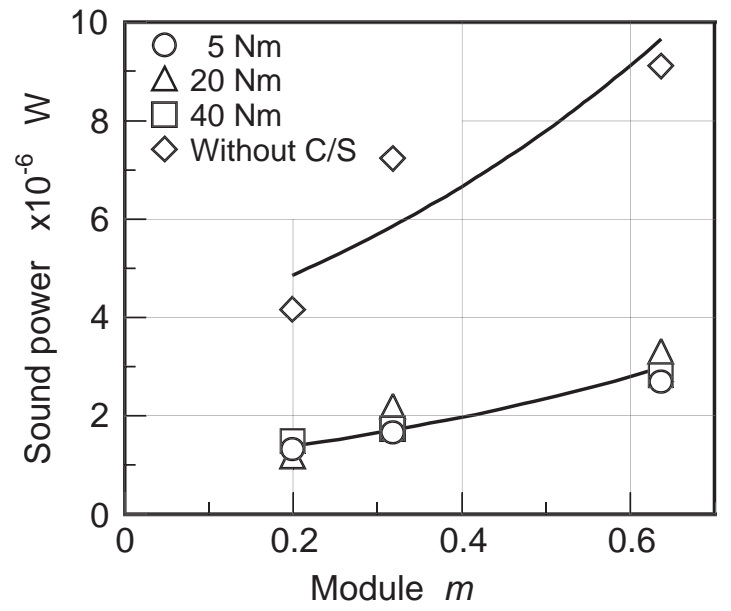

Fig. 7 Relation between sound power and module

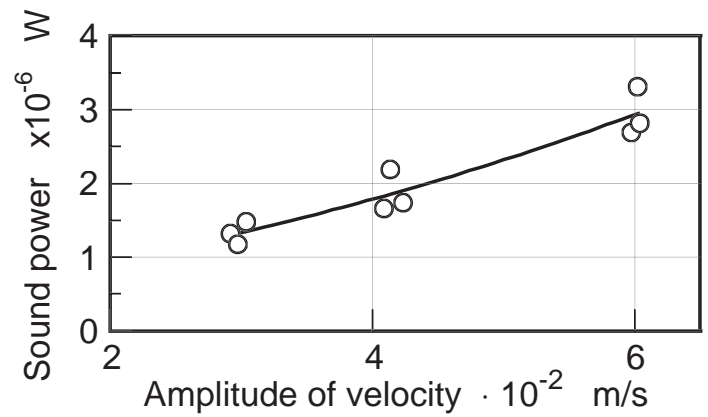

Fig. 8 Relation between amplitude of velocity of F/S and sound power

in the module is higher than that when the $\mathrm{F} / \mathrm{S}$ meshes with the $\mathrm{C} / \mathrm{S}$. It is considered that the absence of the $\mathrm{C} / \mathrm{S}$ enhances the out-of-plane vibration of the cup-shaped $\mathrm{F} / \mathrm{S}$ at the open side. From this result, it is considered that the meshing of teeth suppresses the noise, and that the vibration caused by teeth meshing is negligible with respect to the noise level of strain wave gearing.

Figures 9 and 10 show the sound pressure spectra and the displacement of the F/S, respectively, in the frequency range of $0-1 \mathrm{kHz}$. In both figures, a peak corresponding to fw resulting from out-of-plane vibration of the $\mathrm{F} / \mathrm{S}$ appears, and its superharmonic components are observed. Although not shown in these figures, the peak corresponding to teeth mesh frequency does not appear. The reason is considered to be that the change in meshing stiffness, which generally causes the vibration of gears, is extremely small, because the number of teeth that simultaneously mesh between the $\mathrm{F} / \mathrm{S}$ and the $\mathrm{C} / \mathrm{S}$ is large, as explained previously. Also on the basis of this result, the vibration caused by teeth meshing is found to be negligible. Table 1 shows a summary of the contribution ratio of $f_{w}$ to the overall value of sound pressure in Fig. 9. The contribution ratio is in the range of $32-86 \%$. This value increases with increasing module. Similarly, as input rotary speed increases, the intensity of the fw component increases; however, those of other components also increase. As a result, at an input rotary speed of higher than $2000 \mathrm{~min}^{-1}$, the contribution ratio decreases. On the basis of the above measurement results and discussion, the main cause of noise from strain wave gearing is concluded to be the out-of-plane vibration of the F/S. 


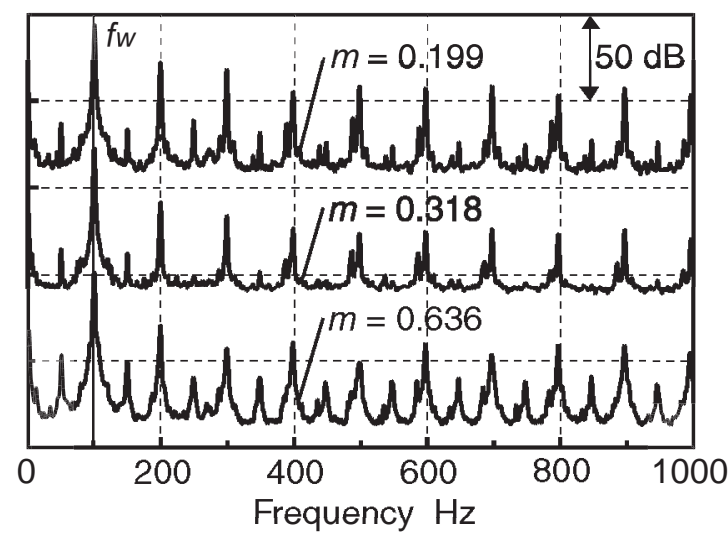

Fig. 9 Spectrum of sound pressure (input speed: $3000 \mathrm{~min}^{-1}$, load: $40 \mathrm{Nm}$ )

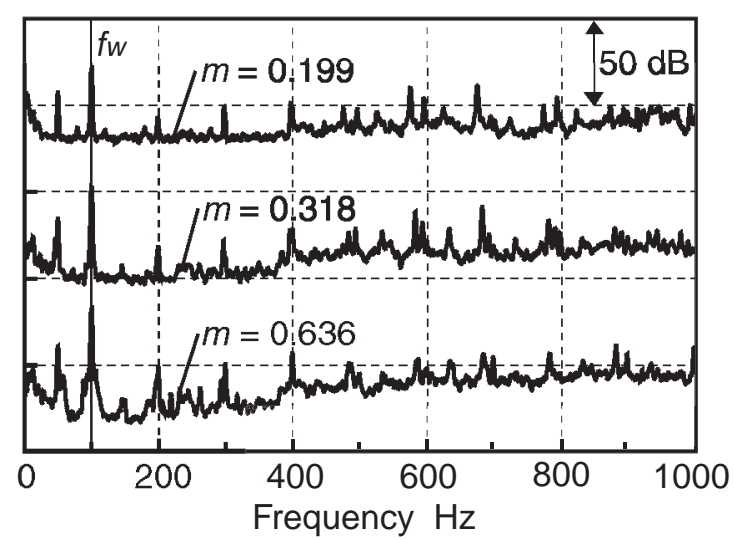

Fig. 10 Spectrum of displacement of F/S (input speed: $3000 \mathrm{~min}^{-1}$, load: $40 \mathrm{Nm}$ )

Table 1 Contribution ratio of $f_{w}$ on sound pressure

\begin{tabular}{r|c|c|c}
\hline $\begin{array}{c}\text { Input speed } \\
\text { Module } \\
0.636\end{array}$ & \\
\hline$f_{w}(\mathrm{~dB})$ & & \\
\hline
\end{tabular}




\subsection{Effect of focused factors on noise generation}

The effect of module on noise was discussed in section 4.1. Figures 11-13 show the relationships between the factors focused on (loaded torque, input rotary speed, and assembly error, respectively) and sound power (left axis) and velocity amplitude (right axis). In each of the figures, measurement was carried out under three module values, i.e., $m$ $=0.199,0.318$, and 0.636. Assembly error was given by inserting a shim between component $\mathrm{A}$, used to fix the F/S, and the base, such that the F/S was eccentrically fixed with respect to the $\mathrm{W} / \mathrm{G}$ and $\mathrm{C} / \mathrm{S}$. As shown in Fig. 11, the velocity amplitude remains constant with increasing loaded torque. Similar results were also obtained by FEM analysis. The sound power remains almost constant regardless of the loaded torque, although there are some deviations. This result agrees fairly well with that estimated on the basis of the noise-generation mechanism explained in section 4.1. In Fig. 12, the velocity amplitude increases with increasing input rotary speed, and sound power increases proportionally with the square of the input rotary speed. This result corresponds to the relationship expressed using Eqs. (1) and (3).

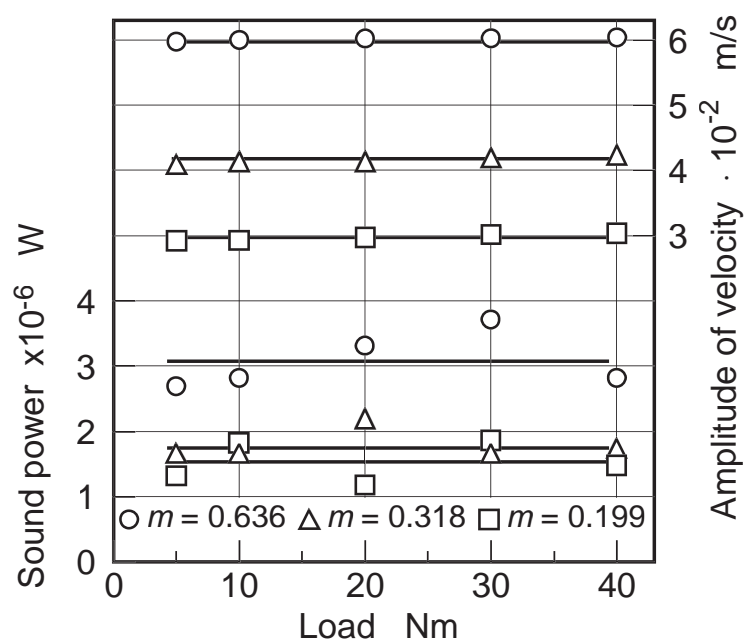

Fig. 11 Relation among sound power, amplitude of velocity and loaded torque (input speed: $3000 \mathrm{~min}^{-1}$ )

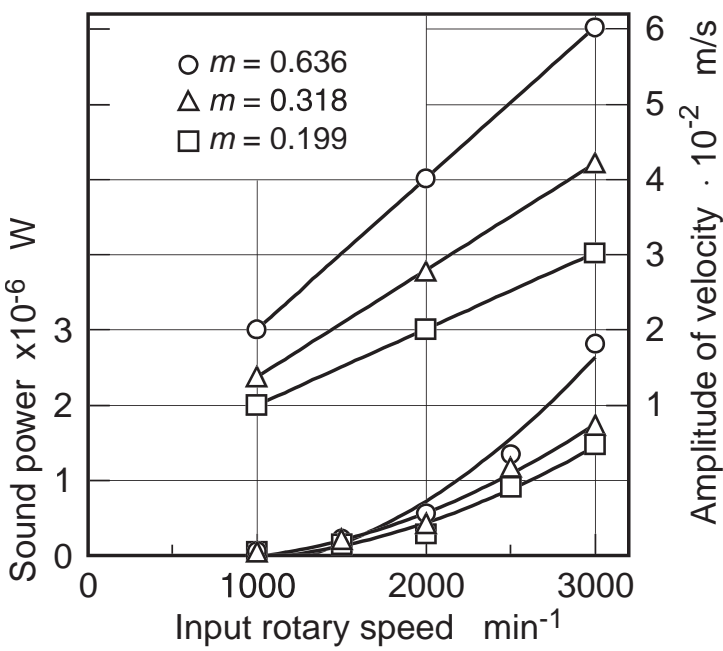

Fig. 12 Relation among sound power, amplitude of displacement and input speed (load: $40 \mathrm{Nm}$ ) 


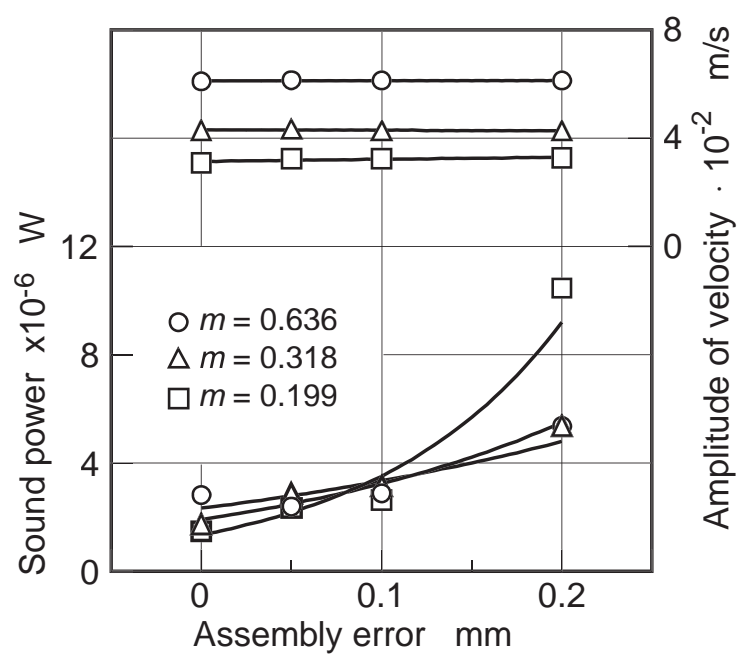

Fig. 13 Relation among sound power, amplitude of velocity and assembly error (input speed: $3000 \mathrm{~min}^{-1}$, load: $40 \mathrm{Nm}$ )

In Fig. 13, the velocity amplitude remains constant, whereas the sound power increases with increasing assembly error. The rate of increase in the sound power, i.e., the effect of eccentricity, is small when the module is small. The constant velocity amplitude was also confirmed by FEM analysis. However, this phenomenon cannot be explained by the above-mentioned noise-generation mechanism because the velocity amplitude of the F/S. Therefore, the sound pressure spectra obtained under each set of conditions were compared. Figure 14 shows the spectra of the sound pressure of the strain wave gearing $(1 / 160)$ with the highest rate of increase in sound power at assembly errors of (a) 0 and (b) $0.2 \mathrm{~mm}$. Furthermore, the results obtained by subtracting the spectrum values under an assembly error of $0 \mathrm{~mm}$ from those under the error of $0.2 \mathrm{~mm}$, followed by normalization (Fig. 14(c)), and the natural frequency of $\mathrm{F} / \mathrm{S}$ alone, obtained by impulse excitation on the side face (Fig. 14 (d)), are also shown to elucidate which frequency component of the spectrum increased.

In Figs. 14(a) and 14(b), peaks are observed at 3.2 and $3.9 \mathrm{kHz}$, and the levels of these peaks are higher in Fig. 14(b) than in Fig. 14(a). However, in Fig. 14(d), peaks are observed at 3.5 and $3.7 \mathrm{kHz}$, which is different from the results in Figs. 14(a) and 14(b). On the basis of this finding, the higher levels of the peaks at 3.2 and $3.9 \mathrm{kHz}$ in Fig. 14(b) than those in Fig. 14(a) cannot be explained on the basis of the intensification of resonance with the F/S. In Fig. 14(c), the sound pressure level increases around the natural frequency of $2.8 \mathrm{kHz}$, as a result of an increase in the assembly errors. The increase in the sound pressure level in the frequency range of $3 \mathrm{kHz}$ or less is large on the whole, and this leads to an increase in the overall sound power level. Figure 15 shows a superposition of Figs. 14(a) and 14(b) in the frequency range of $0-2 \mathrm{kHz}$. When the assembly error is given, peaks are observed at $\mathrm{fm}$, a frequency of the rotary speed of the motor $(50 \mathrm{~Hz}$ in the figure), and its superharmonic component. Although not shown in the figure, similar results were obtained when the rotary speed was changed. When strain wave gearing was operated at the motor rotary speed of as low as a few turns per minute, we confirmed the presence of a vibration that was synchronized with the motor rotation by touching the supporting stand (component B in Fig. 4) of the input shaft with a finger. In Fig. 14(c), the increase in the intensity of the $f_{w}$ component is largest, which is considered to be a result of the increase in the intensity of the $2 f_{m}$ component.

From the above discussions, we conclude that the sound power level increases because the input shaft becomes eccentric due to assembly error, thereby causing vibration; the generated vibration is then transmitted via the $\mathrm{W} / \mathrm{G}$ and radiated from around the $\mathrm{F} / \mathrm{S}$. 

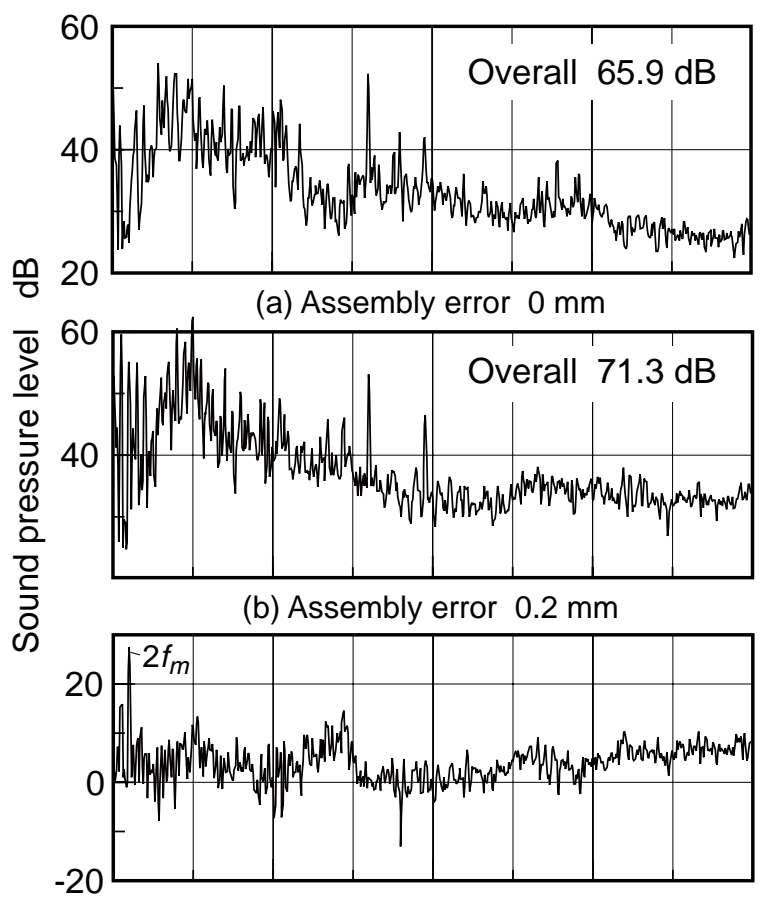

(c) Normalized

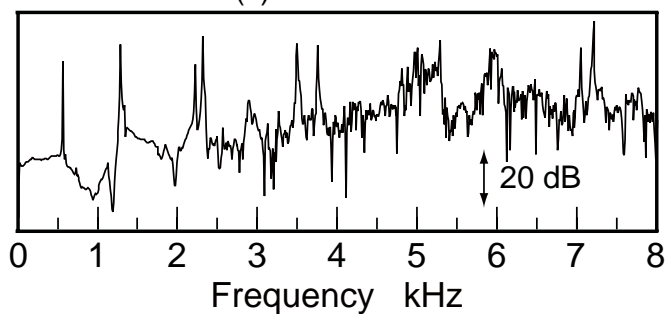

(d) Natural frequency of F/S

Fig. 14 Spectrum of sound pressure level and natural frequency of F/S (input speed: $3000 \mathrm{~min}^{-1}$, load: $40 \mathrm{Nm}$ )

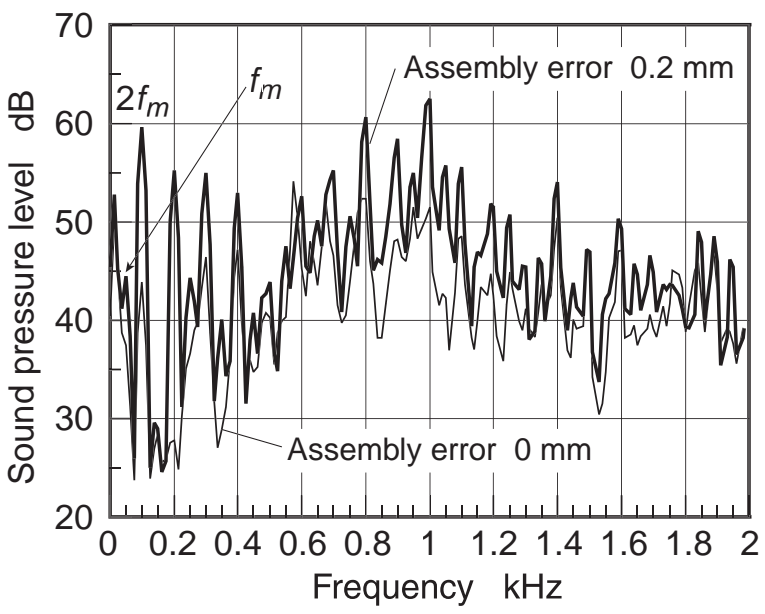

Fig. 15 Comparison of spectrum in narrow range 


\section{Conclusions}

To clarify the noise-generation mechanism of strain wave gearing, the F/S was focused on, and its vibration and radiated noise were measured. We obtained the following results.

(1) The main cause of noise radiated from the strain wave gearing is the out-of-plane vibration of the $\mathrm{F} / \mathrm{S}$. The sound power increases proportionally with the square of the velocity amplitude, as shown in Fig. 8.

(2) The displacement amplitude and sound power remain almost constant with increasing loaded torque.

(3) The sound power increases proportionally with the square of input rotary speed.

(4) When the assembly error is given, the velocity amplitude is unchanged; however, sound power increases owing to the vibration caused by the eccentricity of the input axis.

\section{References}

(1) Ishida, T., Hidaka, T., Zhang, X., Nakane, M., Sasahara, M. and Tanioka, Y., Bending Stress on Flexible Spline of Strain Wave Gearing, Transactions of the Japan Society of Mechanical Engineers, Series C, Vol. 59, No. 567 (1993), pp. 3526-3532.

(2) Zhang, X., Ishida, T., Hidaka, T., Sasahara, M., Kiyosawa, Y. and Maruyama, A., Effect of Assembly Error on Bending Stress on Flexible Spline of Strain Wave Gearing, Transactions of the Japan Society of Mechanical Engineers, Series C, Vol. 62, No.598 (1996), pp. 2442-2449.

(3) Kikuchi, M., Ishibashi, K., Kiyosawa, Y. and Zhang, X., Stress Analysis of Cup Type Strain Wave Gearing, Transactions of the Japan Society of Mechanical Engineers, Series C, Vol. 64, No. 621 (1998), pp. 1604-1610.

(4) Kikuchi, M., Hasegawa, H., Kiyosawa, Y. and Zhang, X., Stress Analysis of Cup Type Strain Wave Gearing (2nd Report, Effect by the Contact with Circular Spline), Transactions of the Japan Society of Mechanical Engineers, Series C, Vol. 67, No. 656 (2001), pp. 900-905.

(5) Sentoku, H., Satou, T., Kiyosawa, Y. and Zhang, X., Characteristic of transmission in Strain Wave Gearing (1st Report, Derivation of Load Distribution on Tooth Flank), Transactions of the Japan Society of Mechanical Engineers, Series C, Vol. 70, No. 696 (2004), pp. 2515-2522.

(6) Hidaka, T., Ishida, T., Zhang, Y., Sentoku, H., Sasahara, M. and Tanioka, Y., Theoretical Analysis of the Vibration in a Robot due to a Strain Wave Gearing, Transactions of the Japan Society of Mechanical Engineers, Series C, Vol. 55, No. 516 (1989), pp.1864 -1871.

(7) Kojima, H., Taguchi, K. and Tuji, H., Robot Vibrations Caused by Torque Ripples in Power transmission Mechanisms, Transactions of the Japan Society of Mechanical Engineers, Series C, Vol. 55, No. 517 (1989), pp. 2390-2395.

(8) Yanabe, S., Ito, A., Okamoto, J., Yamaguchi, T., Ikeda, M. and Fujita, H., Rotational Transmission error of Harmonic drive device, Transactions of the Japan Society of Mechanical Engineers, Series C, Vol. 56, No. 521 (1990), pp. 148-153.

(9) Japan Society of Mechanical Engineers ed., Handbook of Machine Noise (in Japanese), (1991), p. 443, Sangyotosho.

(10) Catalog of Harmonic Drive, Harmonic Drive Systems Inc., available from $<$ http://www.hds.co.jp>, (accessed 2009-2-10).

(11) Japanese Industrial Standard, Acoustics Determination of Sound Power Levels of Noise Sources using Sound Intensity (part 1: Measurement at discreat points), JISZ 8736-1 (1999), Japanese Standards Association. 